\title{
Protection for Sale: An Empirical Investigation: Comment
}

\author{
Theo Eicher* \\ Thomas Osang \# \\ March 2002 \\ Version 2.0
}

\begin{abstract}
Do contributions levels matter for endogenous protection or is the existence of a lobby sufficient? Are lobbies' net benefits from protection identical to their contribution levels, or does the level of protection simply reflect contribution levels of supporters and opponents? We estimate the Influence Driven (Grossman and Helpman, 1994) and the Tariff Function (Findlay and Wellisz, 1982) models within a unified theoretical framework to examine the contrasting implications derived from these two prominent tariff formation models.

We find strong evidence that protection is indeed "for sale." The important new result is, however, that not only the existence of lobbies matters, but also the relative size of the sectoral pro and anti protection contributions. Using $\mathbf{J}$ tests to compare the power of the models directly, we cannot reject the null of correct specification of the Influence Driven model and find evidence of some misspecification in the Tariff Function model.
\end{abstract}

Keywords: Endogenous Protection, Lobbying, Political Economy of Tariffs

JEL Classification: F13, D72, P16

\footnotetext{
"Corresponding author, Department of Economics, University of Washington, Seattle, WA 98195; te@u.washington.edu.

\# Department of Economics, Southern Methodist University, Dallas, TX 75275; Tel: (214) 768-4398, e-mail: tosang@mail.smu.edu.

We thank Charles Engel, Kishore Gawande, Francois Laisney, Myong-jee Lee, Essie Maasoumi as well as seminar participants at the University of Wisconsin, SMU, NBER ITI Winter Meeting 2000, and Texas Camp Econometrics for helpful comments and suggestions. Kishore Gawande and Daniel Treffler kindly provided their datasets.
} 


\section{$1 \quad$ Introduction}

Two curious features are inherent in one of the most prominent approaches to endogenous tariff formation. First, the equilibrium tariff formation equation is independent of the size of a lobby's contribution. While lobbying is modeled with rich and deep game theoretic foundations in Grossman and Helpman's (1994) $(\mathrm{GH})$ Protection for Sale, only the existence of a lobby matters in equilibrium, not its actual contribution level (aside from the government's weight on consumer welfare, and import penetration). Second, the absence of an equilibrium relation between lobbying dollars and tariffs levels arises because GH rely on Bernheim and Whinston's (1986) Truthful Nash Equilibrium concept, where lobby contributions are identical to the net benefit from protection. This result is due to the assumption of a First Price Menu Auction under complete information. Boylan (2000) shows that the tariff function itself is dependent on the assumptions of (in)complete information and on the exact auction rules, which may explain the popular notion that lobbying expenses can dwarf subsequent industry gains.

The central predictions of GH have received empirical support from Goldberg and Maggi (GM) (1999) and Gawande and Bandyopadhyay (GB) (2000). Neither empirical test specified alternatives to the Truthful Nash Equilibrium concept, however, and PAC Contribution levels are employed to proxy the existence of a lobby. ${ }^{1}$ An alternative hypothesis would be to estimate a model of endogenous protection which incorporates contributions directly and which does not rely on complete information. With minor modifications to the Protection for Sale framework, one can examine the effects of the contribution levels on industry tariffs without having to rely on Truthful Nash Equilibria. In this paper we specify this alternative hypothesis by building on Findlay and Wellisz' (1982) Tariff Formation Function model. In Findlay and Wellisz, lobbying expenditures directly influence the resulting tariff, and contributions need not equal the net-benefit from protection as lobbying maximize profits by equating the marginal lobbying dollar to marginal lobbying costs.

1 GM use a absolute threshold contribution size as an indicator, in effect establishing a step function where only industries with sufficiently large contributions are judged "organized." GB regress contributions scaled by value added on bilateral import penetration interacted with SIC dummies. Positive coefficients then identify organized industries. 
We employ a unified theoretical framework to estimate both models and to examine which of the two models performs better in terms of its predictions regarding tariff formation. The theoretical framework highlights how closely related the two models are, since the Tariff Formation Function model can be seen as a sub-component of the Influence Driven model. Abstracting from the Truthful Nash Equilibrium concept, from complete information, and from government preferences over aggregate welfare in the Influence Driven model, the Tariff Formation Function model emerges naturally.

In our estimations both approaches perform strongly. All coefficients are of the correct sign and significant at the one percent level. The size of sectoral contributions is shown to have a strong positive impact on tariffs, and in the absence of lobbying contributions, the relationship between import penetration and endogenous protection is positive. The weight of supporters' contributions in the tariff formation function is estimated to be twice as large as the one associated with contributions of tariff opponents. Alternatively, our estimations of GH indicate that protection is a) greater in industries represented by lobbies and with lower import elasticities, b) increasing with import penetration in unorganized sectors, c) decreasing with import penetration in organized sectors. While our estimated government weight on aggregate welfare is very similar to GM, our estimates indicate that about 26 percent of the population owns sector specific inputs, a more realistic number than the 88 percent estimated by GM.

Since both models perform well when taken to the data, the question arises whether it is contributions or organization that matters for endogenous protection - especially since the organization indicator is generated using contribution data. We find that the key variable of the Influence Driven model (the indicator variable of the existence of a lobby) seems to be more significant than the size of lobbying contributions expenditures. Since the Indicator variable is itself constructed from lobbying data (following GM) we conclude that the step function approach seems to be better than the continuous contribution schedule. ${ }^{2}$

To formally juxtapose the two models, we employ J-Tests and cannot reject the null of correct specification of the Influence Driven model, but find evidence of some misspecification in

\footnotetext{
${ }^{2}$ We thank Charles Engel for pointing out this detail.
} 
the Tariff Function. Our results provide additional support for the strength and robustness of the Influence Driven model and new evidence to underline the significance of the Tariff Function model in explaining endogenous protection.

Our tests of the strict theories add to the voluminous empirical literature on protection that focused on heuristic or general factor endowment approaches, such as Ray (1981), Baldwin (1985), or Trefler (1993). Especially interesting is the comparison of our results to the findings of previous reduced form juxtapositions of endogenous tariff formation models in Gawande (1998). Similar to our results he finds that the political-self-interest/special-interest model performs best against alternative models. Interesting is also the comparison between our results and GB, who test the implications predicted of the GH model, as they relate to lobbying competition. GB find strong evidence that contributions depend on the cloud of industry rivals another confirmation of the Truthful Nash Equilibrium concept that GH propose.

\section{Theoretical Approaches to Endogenous Protection}

The unified theoretical framework is a succinct representation of Helpman (1997), who discusses both the motivations and full derivations. Consider a continuum of individuals, $j$, populate an economy whose population size is normalized to unity. Each individual possesses a utility function

$$
u(c)=c_{o}+\sum_{i=1}^{n} u_{i}\left(c_{i}\right)
$$

Where $c_{i}$ is consumption of product $i$. A numeraire good, indexed 0 , uses one unit of labor per unit output. All other products use labor and a sector-specific input.

An individual owns $l^{j}$ of the aggregate labor supply, and $\gamma_{i}^{j}$ of the sectors' specific input. The wage rate then equals one, and the return to a sector specific input, $\Pi_{i}\left(p_{i}\right)$, is an increasing function of the producer price, $p_{i}$. Let aggregate imports be denoted by $M_{i}$, and normalize all foreign prices to unity, which implies $p_{i}=\tau_{i}$, and $\tau_{i}>1$ for positive rates of protection. The government redistributes tariff revenues lump-sum, and uniformly to all individuals. The reduced form of the indirect utility function can then be written as an additive 
composite of the incomes derived from labor, transfers, specific factor incomes, and consumer surplus, $S_{i}$ :

$$
\hat{v}\left(\tau, \gamma^{j}\right)=l^{j}+\sum_{i=1}^{n}\left(\tau_{i}-1\right) M_{i}\left(\tau_{i}\right)+\sum_{i=1}^{n} \gamma_{i}^{j} \Pi_{i}\left(\tau_{i}\right)+\sum_{i=1}^{n} S_{i}\left(\tau_{i}\right)
$$

Integrating over all individuals' indirect utilities, aggregate welfare becomes

$$
W(\tau)=1+\sum_{i=1}^{n}\left(\tau_{i}-1\right) M_{i}\left(\tau_{i}\right)+\sum_{i=1}^{n} \Pi_{i}\left(\tau_{i}\right)+\sum_{i=1}^{n} S_{i}\left(\tau_{i}\right)
$$

These general definitions of indirect utility and welfare can be used to derive two distinct models of endogenous protection, depending on alternative political economy processes.

\subsection{The Tariff Function Approach}

Findlay and Wellisz (1982) pioneered the approach where pro and anti protectionists "invest" in the political process, so that the outcome, a tariff, is the result of a lobbying contest. How responsive the tariff is to the respective groups' lobbying is given by a tariff function, $\tau_{i}=T\left(C_{i}^{S}, C_{i}^{O}\right)$, with $\partial T / \partial C_{i}^{S}>0$ and $\partial T / \partial C_{i}^{O}<0$, where $C_{i}^{S}$ and $C_{i}^{O}$ represent the respective expenditures of protection supporters and opponents. A lobby maximizes joint welfare, $W_{i}^{s}\left(\tau_{i}\right)$, of its participants

$$
W_{i}^{s}\left(\tau_{i}\right)=l^{j}+\Pi_{i}\left(\tau_{i}\right)+\alpha_{i}\left(\tau_{i}-1\right) M_{i}\left(\tau_{i}\right)+S_{i}\left(\tau_{i}\right) .
$$

where $\alpha_{i}$ is the fractions of the population that own specific factor in sector $i$. Joint welfare can again be written as an additive composite of labor and specific factor income, plus the lobby's share of the tariff rebate, in addition to the consumer surplus. The marginal benefit to protection of the supporters of protection then equals $W_{i}^{s^{\prime}}=\left(1-\alpha_{i}\right) X_{i}+\alpha_{i}\left(\tau_{i}-1\right) M_{i}^{\prime}$, which is positive for small values of $\tau_{i}$.

The antagonists of the owners of the specific factor in sector $i$ form a lobby to oppose protection. This group's joint welfare is

$$
W_{i}^{o}\left(\tau_{i}\right)=\left(1-\alpha_{i}\right)\left[\left(\tau_{i}-1\right) M_{i}\left(\tau_{i}\right)+S_{i}\left(\tau_{i}\right)\right],
$$

which implies that $1-\alpha_{i}$ of the tariff rebate and consumer surplus is recaptured. The marginal benefit of the opponents of protection, $W_{i}^{o^{\prime}}=\left(1-\alpha_{i}\right)\left[-X_{i}+\left(\tau_{i}-1\right) M_{i}^{\prime}\right]$, is negative for positive tariff rates. 
An interior equilibrium of the non-cooperative game between the interest groups requires that the marginal benefit to joint welfare equals the partial derivatives of the tariff function with respect to the spending level of each lobby (the marginal cost). These additional conditions (one for each group) yield the tariff function

$$
\tau_{i}-1=\frac{\left(1-\alpha_{i}\right)\left(b_{i}-1\right)}{\alpha_{i} b_{i}+\left(1-\alpha_{i}\right)} \frac{X_{i}}{\left(-M_{i}^{\prime}\right)},
$$

where $b_{i}$ is the marginal rate of substitution between the supporters' and opponents' spending levels in the tariff function. The Tariff Function approach thus implies that a sector is protected if and only if this ratio of elasticities exceeds unity, or $b_{i}>1$. This implies that a sector is only protected if a dollar spent by pro-protectionists raises the tariff by more than it declines due to a dollar spent by anti protectionists. If both sides' expenditures are equally potent in influencing the tariff function with an additional dollar, free trade will result. In addition, if a sector is protected, the tariff increases in the fraction of people in the population that belong to the protectionist group. The tariff increases in the sector's output level and in the elasticity of the import demand function. ${ }^{3}$

\subsection{The Influence-Driven Approach}

In the Influence Driven model interest groups maximize benefits to their members and offer politicians campaign contributions to influence their policy stance. Politicians maximize their own political objective function, which depends on contributions and on the well being of the general public. Suppose the political objective function that the policy maker maximizes is $(1-\beta) C+\beta W$, where $C=\sum_{i} C_{i}$ stands for the sum of campaign contributions from all sectors, $W$ represents aggregate welfare, and $\beta$ is a parameter that represents the weight the government places on welfare considerations. If a sector does not contribute to the campaign, the policy maker disregards that sector's special interest concerns. Suppose that in some subset of the sectors, $L \subset\{1,2, \ldots, n\}$, the owners of the sector-specific inputs form lobbies. The aggregate welfare of the interest group is then given by 


$$
W_{i}(\tau)=l_{i}+\Pi_{i}\left(\tau_{i}\right)+\alpha_{i} \sum_{j=1}^{n}\left[\left(\tau_{j}-1\right) M_{j}\left(\tau_{j}\right)+S_{j}\left(\tau_{j}\right)\right]
$$

which includes again labor and specific factor incomes as well as the tariff rebates and consumer surplus. The lobby maximizes $W_{i}(\tau)-C_{i}$ and takes the contribution functions of all the other interest groups $j \neq i, C_{j}(\tau)$, as given. The size of the contribution is determined by the condition that the lobby must contribute sufficiently to raise the policy maker's welfare above $G_{-i}=\max _{\tau}\left[(1-\beta) \Sigma_{j \neq i} C_{j}(\tau)+\beta W(\tau)\right]$, which is the level generated in the absence of lobby $i$ 's contribution. In short, the standard participation constraint in principal-agent problems requires that in equilibrium contributions equal

$$
C_{i}(\tau)=G_{-i}-\left[(1-\beta) \sum_{j \neq i} C_{j}(\tau)+\beta W(\tau)\right]
$$

This implies that interest groups lobby not only for their own cause, but for an entire tariff policy vector, that maximizes each lobby's objective function $W_{i}(\tau)-C_{i}$

$$
\tau^{i} \in \arg \max _{\tau} W_{i}(\tau)+\left[(1-\beta) \sum_{j \neq i} C_{j}(\tau)+\beta W(\tau)\right] .
$$

As lobbies make offers that relate contributions to levels of protection, the truthful Nash equilibrium concept under full information stipulates that contributions are identical to the net benefit that each tariff generates for the lobby. The government then maximizes its welfare function, subject to the contribution schedules, resulting in the tariff function

$$
\tau_{j}-1=\frac{I_{j}-\alpha_{L}}{\beta /(1-\beta)+\alpha_{L}} \frac{X_{j}}{-\left(M_{j}^{\prime}\right)},
$$

where $\alpha_{L}=\sum_{j \in L} \alpha_{j}$ stands for the fraction of people that own sector specific inputs and $I_{j}$ is a dummy that is one if, $i \in L$, the sector is organized, and zero otherwise.

In the extreme case, when all sectors have organized pressure groups and every individual has a stake in some sector, there is free trade. From (9) we find that the rate of protection in sector $i$ increases in the concentration of the ownership in that sector's specific

\footnotetext{
${ }^{3}$ Feenstra and Bhagwati (1982) extend the Findlay and Wellisz framework to allow for a government that cares not only about the lobbyists' welfare, but also about the general public; a theme subsequently developed fully by the Influence Driven approach.
} 
factor, since the greater the concentration, the less the lobby cares about dead weight loss. The tariff also increases in the weight the policy maker places on contributions relative to welfare, since it becomes "cheaper" to influence the policy maker with contributions. The effects of output and of the slope of the import demand function are the same as in the formulas that derived for the Political Support Function approach, and the Tariff Function approach. However there is an added twist to the model. For protected sectors, $I=1$, the tariff rate should decrease in the import penetration ratio. This is because the larger the domestic output, the more owners of specific factors gain from an increase in the domestic price, while the economy as a whole incurs fewer inefficiency losses when the volume of imports is low, ceteris paribus. For unprotected sectors, the relationship between tariffs and import penetration is positive.

\section{Empirical Methodology}

The estimation of the competing approaches contained in equations (6), and (9) requires several simplifying assumptions. First, we follow the procedure of GM and move the import elasticities to the left-hand side to counter measurement errors. ${ }^{4}$ Second, we assume that the elasticities in equations (6) and (9) are constant across sectors. We use a Wald Test to check the validity of this assumption and we cannot reject the null hypothesis of parameter stability at the $1 \%$ significance level for neither model. ${ }^{5}$ Third, the Tariff Formation Function model requires us to assume a specific functional form for the tariff function to take the model to the data. Furthermore we assume increasing returns to lobbying (to reflect the real world observation that large donors command relatively greater influence). The simplest form is then $T[]=.\lambda\left(C^{s}\right)^{2}-(1-\lambda)\left(C^{O}\right)^{2}$, where $\lambda$ and $1-\lambda$ indicate the respective weights of proponents and opponents contributions in the Tariff Function. We also assume that the concentration of ownership is small relative to the rest of the population so that $\alpha_{i} /\left(1-\alpha_{i}\right)$

\footnotetext{
${ }^{4}$ G-B have improved the estimation procedure by utilizing the standard errors on the elasticities. We maintain the GM methodology for comparison purposes.

${ }^{5}$ Dividing the sample randomly, we perform a Wald test $\Lambda_{1}=\left(\hat{\theta_{1}}-\hat{\theta_{2}}\right)^{\prime}\left(V_{1}+V_{2}\right)^{-1}\left(\hat{\theta_{1}}-\hat{\theta_{2}}\right)$, which has a chi-squared distribution with $\mathrm{k}$ degrees of freedom where $\mathrm{k}=2$ in (6a) and (9a), and $\mathrm{k}=4$ in (11). To estimate $\Lambda_{1}$, we replace $V_{1}$ and $V_{2}$ by their estimated values. The test statistics and the corresponding p-values for each model are provided in the last row Tables 1.
} 
approaches zero. The approximation error introduced by this assumption is small if the number of industries is large and if ownership of the specific factor is fairly evenly distributed among the population.

The two empirical models that we estimate are given by

Tariff Function

$$
\frac{\tau_{i}^{*}}{\tau_{i}^{*}+1} e_{i}=a_{2} \frac{C_{i}^{S}}{C_{i}^{O}} \frac{1}{z_{i}}+a_{3} \frac{1}{z_{i}}+\varepsilon_{2 i}
$$

Influence Driven Contributions $\frac{\tau_{i}{ }^{*}}{\tau_{i}{ }^{*}+1} e_{i}=a_{4} I_{i} \frac{1}{z_{i}}+a_{5} \frac{1}{z_{i}}+\varepsilon_{3 i}$,

where $\tau_{i}^{*}=\tau_{i}-1, e_{i}$ is the import demand elasticity, $z_{i}=M_{i} / X_{i}$ is the import penetration ratio, and $\varepsilon_{j i}$ is a disturbance term that captures the effects of omitted variables and/or measurement errors in the dependent variable. Like GM we have added the error term additively. A Tobit estimation is necessary for (6a) and (9a) due to the censoring of the dependent variable at zero.

There are both theoretical and empirical reasons to question the exogeneity of the independent variables in (6a), and (9a) (see Trefler, 1993 and GM, for a discussion). To correct for the possible bias in the estimates caused by the endogeneity of the explanatory variables, we employ instrumental variables. To allow for a comparison between our estimation results with those reported by GM, we adopt their list of instruments.

In contrast to GM, who use maximum likelihood, we apply the minimum distance estimator (MDE). The MDE approach is well suited for the case of models with censored data and potential endogeneity of the exogenous variables (see Lee, 1996, chapter 6). The MDE is also not based on any normality assumption typical for maximum likelihood estimators. The data is discussed in the appendix.

\section{Empirical Results}

\subsection{Tariff Function}

Translating contributions of the "supporters" and "opponents" of tariffs in each sector from the theory into the real world requires some interpretation. In the spirit of Findlay and Wellisz, supporters of protection in sector $i$ would be that sector's owners of factors and 
workers, at least in the short run. Lobbying against would be the factor owners and workers in all other sectors. Hence we aggregate union and firm contributions in each sector and divide by the contributions of all unions and firms. ${ }^{6}$

The model carries two predictions. First, since Helpman (1997) augmented Findlay and Wellisz to explicitly include consumer surplus, the effect of import penetration on tariffs is negative in the absence of contributions. Second, the model predicts that the greater the contributions of supporters relative to opponents of protection, the larger the negative impact of import penetration on tariffs.

The Tariff Function model performs surprisingly well. Both parameter estimates are significant at the one percent level and exhibit the right sign. An increase in the sectoral contributions relative to other sectors has a surprisingly large effect on the dependent variable. The implied weight of the contributions of supporters of tariffs, $\lambda$, is estimated to be 66 , implying that the tariff function weighs contributions from pro lobbies twice as much as those from tariff opponents.

In their sensitivity analysis GM proposed an analog out our Tariff Function equation above and tested if continuous contributions, rather than a dummy in the tariff equation would yield different results - without success. Here the alternative to the influence driven model is clearly theoretically derived and specified. Our specification also derives specific weights on pro and anti tariff lobby contributions in the tariff function.

\subsection{Influence Driven}

The estimates of the Influence Driven model are in line with the estimates reported in GM. Small differences remain due to both minor differences in the data set and different estimation procedures. ${ }^{7}$ If anything, this should be seen as a strong confirmation of the results obtained by GM. ${ }^{8}$

\footnotetext{
${ }^{6}$ Alternative specifications pitting firms against unions in each sector did not generate plausible results. Baldwin and Magee (1998) find that votes in Congress against (for) freer trade are associated with aggregate contributions of Labor (business).

${ }^{7} \mathrm{We}$ did not receive the GM data set. In reconstructing the 3 digit SIC level data set from 4 digit level data, our sample contained 106 SIC industries compared to 107 in GM, most likely because we have to construct an additional variable to test the Tariff Function approach. Another difference to GM is that we use an updated version of the NBER Manufacturing Productivity database. Also, GM use contribution data from
} 
As the theory predicts, the estimates show that in addition to the positive effect of import penetration on the dependent variable, there is a negative effect of import penetration on non-tariff barriers for organized industries (i.e. for industries with firm contributions above a certain, exogenously determined threshold). Thus we confirm the GH proposition at the 1 percent significance level, that whether or not a sector is organized is crucial role to the relationship between import penetration and protection.

Based on the coefficient estimates, the implied value for the government weight on welfare, $\beta, 0.96$ (0.986 in GM), while the fraction of the population that owns sector specific inputs, $\alpha_{L}$, is $0.26(0.88$ in GM). It is notable that GM estimate a significantly higher level of ownership of the sector specific input, although the government's weight on welfare is very similar. The estimates in our model and in GM are significant at the 1 percent level, hence the strong difference in the estimates for the degree of concentration within a sector is likely due to the differences in the estimation method. While our results in this section are similar to GM, they contrast to those of G-B, who find that the respective government weighs on aggregate welfare and contributions are about the same. In case studies, governments are generally found to be significantly more concerned about welfare (see Hufbauer et. al. 1986 as cited by of G-B).

All sign predictions were correct in GM, however, their estimation method did not yield a significant positive sign for the key third prediction, that $a_{5}+a_{4}>0$ in equation (6a) implying that the relationship between import penetration and protection is negative within the set of organized sectors. We find that $a_{5}+a_{4}>0$ is significant at the 1 percent significance level (with a t-statistic of 5.905). We therefore reject the null and can state with some confidence that $a_{5}+a_{4}>0$. Hence we provide additional strong support for the $\mathrm{GH}$ approach in that all its predictions are strongly reflected in the data.

The goodness of fit of the Influence Driven model is better than the fit in the previous model, but only marginally so. This adds empirical evidence to the discussion of the effect of

the 1981-82 campaign, while we use data from the 83-84 campaign. Finally, GM IV estimates are based on maximum likelihood estimates compared to the minimum distance estimator approach applied in this study.

${ }^{8} \mathrm{GM}$ conduct extensive sensitivity analysis. Their results are robust and the same pertains to the results above. 
import penetration on endogenous protection. Several previous studies have found that NTB coverage increases with import penetration (i.e., Finger and Harrision 1996, Lee and Swagel 1997) or with the change in import penetration (Treffler 1993). Only the tests of the GH model by GM and G-B find evidence to the contrary as they take the exact theory to the data. Both find a negative influence although not statistically significant. ${ }^{9}$ Maggi and Rodriguez-Clare (2000) provide a succinct model how positive and negative impacts can be reconciled, by introducing further policy tools (VER's and quotas) to the government in GH.

\section{Model Comparisons}

Both the Tariff Function and the Influence Driven model perform exceedingly well. This raises the question whether one of the highly significant models hold unambiguously more explanatory power. This question goes beyond a comparison of the goodness of fit, it addresses the issue of correct specification of the exogenous variables. In this section we employ non-nested hypothesis testing in form of $\mathrm{J}$ tests to further evaluate the relative strength of each exact theoretical model in explaining endogenous protection. Our methodology is to test the relative strength of each model against each of the two competing alternatives. We follow the test procedure for non-nested J tests developed by Davidson and MacKinnon (1981). ${ }^{10}$ An insignificant coefficient estimate in Table 2 indicates that the null hypothesis can be rejected, implying that the alternative hypothesis does not add significant estimation power to the null hypothesis.

Table 2 provides surprisingly powerful evidence in favor of the Influence Driven model, as the $\mathbf{J}$ tests reject the Null that the Tariff Function model is the true model. In both cases the addition of the Influence Driven model's variables - specifically the information whether a sector is organized or not - turns out to add significant information in estimating endogenous protection.

\footnotetext{
${ }^{9} \mathrm{GH}$ emphasize that the result is dependent on the relative magnitudes of import penetration and import demand elasticities across sectors. Only GM and GB have previously controlled for sectoral differences in these elasticities.

${ }^{10}$ The intuition of the $\mathrm{J}$ tests is the following. Suppose the truth (the null hypothesis) we wish to test is $H_{0}=y_{i}=f_{i}\left(\lambda_{i}, a\right)+\varepsilon_{0 i}$ where $a$ is a vector of parameters to be estimated and $\lambda_{i}$ is a vector of observations on exogenous variables. Suppose theory suggests an alternative hypothesis $H_{1}=y_{i}{ }_{i}=g_{i}\left(\lambda_{i}{ }^{\prime}, a^{\prime}\right)+\varepsilon_{1 i}$ where $a^{\prime}$ and $\lambda_{i}{ }^{\prime}$ are different vectors of parameters and observations. The $\mathrm{J}$ test tests for $\kappa=0$ in
} 
The interpretations of the $\mathrm{J}$ test results add important further information to Table 1 . The Influence Driven model had the best fit in Table 1, nevertheless, it is still surprising that it "beat" the tariff formation function model so soundly in the $\mathrm{J}$ tests.

\section{$7 \quad$ Summary and Conclusions}

In this paper we estimated two alternative endogenous protection models to examine whether contributions or organization matters. The previous literature such as GH and GB rely on a complete information menu auction that renders organization, rather than contribution sizes as the key determinant for tariffs. The model performs well against the Tariff Formation function model where contributions directly influence tariffs, and where non-cooperative solutions do not imply zero net benefits to lobbying as in GH. Since the organization variable is constructed using contributions the fundamental insight is that a step function performs better than the continuous contribution variable in estimating the influence of lobbies on protection.

\section{Appendix: Description of Variables}

Import demand elasticities, $e_{i}$, are taken from Sheills, Stern, and Deardorff (1986). Following GM, the small number of industries with positive import demand elasticities are set to zero.

Non-tariff barriers (NTBs), $\tau_{i}$, (Trefler 1993), aggregated to the three-digit level using as weights the value of shipment.

Import penetration ratio, $z$, (Trefler 1993), aggregated to the three-digit level using as weights the value of shipments

Instrumental variables, (Trefler 1993), aggregated to the three-digit level using as weights the value of shipment.

Political Action Committee contributions, total firm and union contributions by sector obtained for the 1983-84 congressional elections (Gawande, 1998); firm and union spending is multiplied by the number of firms and unions to obtain totals.

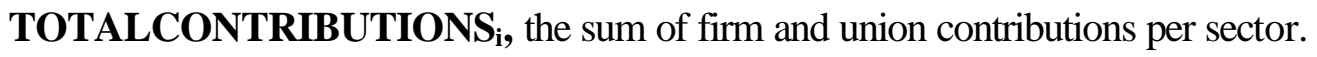

ORGANIZED firm contribution dummy, defined as in GM.

We follow GM in the construction of the key data, Political Action Committee contributions, non-tariff barriers, import penetration ratios and import elasticities. We thus use U.S. data for 106 manufacturing industries at the three-digit SIC level for 1983. Estimates of import demand elasticities are not available at the four-digit SIC level; hence we base this study on three-digit level data. The data on non-tariff barriers (NTBs), $\tau_{i}$, import penetration ratio, $z$, and the instrumental variables used in the Tobit IV estimates are taken from Trefler (1993), but

$y_{i}=\kappa f_{i}\left(\lambda_{i}, a\right)+(1-\kappa) g_{i}\left(\lambda_{i}{ }^{\prime}, \hat{a}^{\prime}\right)+\varepsilon_{i}$ where $\hat{a}^{\prime}$ is the ML estimate of $a^{\prime}$. See Davidson and MacKinnon (1981) for details. 
aggregated to the three-digit level using as weights the value of shipment, obtained from the 1996 NBER productivity database. Import demand elasticities, $e_{i}$, are taken from Sheills, Stern, and Deardorff (1986). ${ }^{11}$ Gawande obtained Political Action Committee contributions for firms and unions in each sector for the 1983-84 congressional elections; they constitute spending per firm and union multiplied by the number of firms and unions to obtain totals. TOTALCONTRIBUTIONS ${ }_{\mathrm{i}}$, represents the sum of firm and union contributions in a sector. For the organization dummy, ORGANIZED, we use the same contribution threshold for firm contribution data as GM.

Table 1: Strictly Theory Based Tests of Endogenous Protection Models

\begin{tabular}{|c|c|c|}
\hline Dependent Variable $\frac{\tau_{i}^{*}}{1+\tau_{i}^{*}} e_{i}$ & $\begin{array}{l}\text { Tariff } \\
\text { Function }\end{array}$ & $\begin{array}{l}\text { Influence } \\
\text { Driven }\end{array}$ \\
\hline$\frac{1}{\operatorname{ImportPenetration}\left(z_{i}\right)}$ & $\begin{array}{l}-.0128 * * * \\
(6.30)\end{array}$ & $\begin{array}{l}-.0098 * * * \\
(4.3073)\end{array}$ \\
\hline $\begin{array}{ll}\text { TOTALCONTRBUTIONS } & \left(C_{i}^{S}\right) \\
\end{array}$ & $1.904 * * *$ & \\
\hline 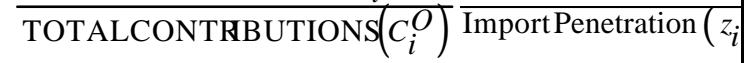 & & \\
\hline $\operatorname{ORGANIZED}(I) * \frac{1}{\text { ImportPenetration }\left(z_{i}\right)}$ & & $\begin{array}{l}.0374 * * * \\
(7.265)\end{array}$ \\
\hline Log-Likelihood & -52.80 & -51.66 \\
\hline $\begin{array}{l}\text { Wald Test, } \Lambda \\
\text { (p-value) }\end{array}$ & $\begin{array}{l}6.465 \\
(.0395)\end{array}$ & $\begin{array}{l}7.7385 \\
(.0209)\end{array}$ \\
\hline
\end{tabular}

$* * * / * * / *$ : Significant at the $1 \% / 5 \% / 10 \%$ level (t-statistics in parentheses)

Table 2: Non-Nested Hypothesis Testing

\begin{tabular}{|l|l|l|l|}
\hline Null Hypothesis & $\begin{array}{l}\text { Alternative } \\
\text { Hypothesis }\end{array}$ & $\begin{array}{l}\text { J-Test } \\
\text { Statistic }\end{array}$ & Interpretation \\
\hline Tariff Function & Influence Driven & .999 & Reject null hypothesis \\
\hline Influence Driven & Tariff Function & $2.79 * * *$ & Cannot reject null hypothesis \\
\hline
\end{tabular}

Not being able to rejecting the null hypothesis implies that the model associated with the null hypothesis is the "correct model" in the sense that information added by the alternative hypothesis does not improve the estimation of the dependent variable.

\footnotetext{
${ }^{11}$ Some industries has positive import demand elasticities, following GM, we set these elasticities to zero.
} 


\section{References}

Baldwin, R. and C. Magee, (1998), Is Trade Policy for Sale? Congressional Voting on Recent Trade Bills, NBER Working Paper 6376.

Baldwin, R., (1985), The Political Economy of U.S. Import Policy, MIT Press)

Davidson, R., and J.G. MacKinnon, (1981), Several Tests for Model Specification in the Presence of Alternative Hypothesis, Econometrica, 49:781-793.

Feenstra, R. and J. Bhagwati, (1982), Tariff Seeking and the Efficient Tariff, in J. Bhagwati, ed., Import Competition and Response, Chicago: U. Chicago Press.

Finger,J. M. and A. Harrison, (1996), The MFA Paradox: More Protection and More Trade?, in Anne O. Krueger, ed, The Political Economy of American Trade Policy. NBER Project Report Series. Chicago: University of Chicago Press.

Findlay, R., and S. Wellisz, (1982), Endogenous Tariffs, the Political Economy of Trade Restrictions, and Welfare, in Jagdish Bhagwati (ed.), Import Competition and Response, Chicago: University of Chicago Press.

Gawande, K. (1998), Comparing Theories of Endogenous Protection: Model Comparisons Using Gibbs Sampling Output, Review of Economics and Statistics, 80: 128-40.

Gawande, K., and U. Bandyopadhyay, (2000), Is Protection for Sale? Evidence on the Grossman-Helpman Theory of Endogenous Protection, Review of Economics and Statistics 82:139-52.

Goldberg, P. K. and G. Maggi, (1999), Protection for Sale: An Empirical Investigation, American Economic Review, 89(5): 1135-1155.

Grossman, G., and E. Helpman, (1994), Protection for Sale, American Economic Review, 84: 833-850.

Helpman, E., (1997), Politics and Trade Policy, in Advances in Economics and Econometrics: Theory and Application, David Kreps and Kenneth Wallis eds., Cambridge: Cambridge University Press.

Hufbauer, G., D. Berliner and K. Elliot, (1986), Trade and Protection in the US: 31 Case Studies (Washington DC: Institute for International Economics)

Lee, J.W. and P. Swagel, (1997), Trade Barriers and Trade Flows across Countries and Industries, Review of Economics and Statistics; 79:372-82.

Lee, M.J., (1996), Methods of Moments and Semiparametric Econometrics for Limited Dependent Variable Models, New York: Springer Verlag.

Magee, S. P., W.A. Brock and Leslie Young, (1989), Black Hole Tariffs and Endogenous Policy Theory, Cambridge: Cambridge Univ. Press

Maggi, G. and A. Rodriguez-Clare, 2000, Import Penetration and Politics of Trade Protection, Journal of International Economics, 51, 2:287-305

Ray, E.J., (1981), The Determinants of Tariff and Non-Tariff Trade Restrictions in the United States, Journal of Political Economy, 89:105-121.

Shiells, C. R., Stern, R. M., and A.V. Deardorff, (1986), Estimates of the Elasticities of Substitution between Imports and Home Goods for the United States, Weltwirtschaftliches Archiv, 122: 497-519. 
Trefler, D., (1993), Trade Liberalization and the Theory of Endogenous Protection: An Econometric Study of U.S. Import Policy, Journal of Political Economy, 101(1):138160. 